\title{
Phylogenetic analysis of the Australasian paralysis ticks and their relatives (Ixodidae: Ixodes: Sternalixodes)
}

Mackenzie L. Kwak', lan Beveridge ${ }^{1}$, Anson V. Koehler ${ }^{1}$, Mallik Malipatil ${ }^{2,3}$, Robin B. Gasser ${ }^{1}$ and Abdul Jabbar ${ }^{\text {* }}$

\begin{abstract}
Background: The Australasian paralysis ticks and their relatives, Ixodes Latrielle, subgenus Sternalixodes Schulze, are some of the most important ticks in the region. However, very little is known about their phylogenetic relationships. The aim of this study was to elucidate the evolutionary relationships of members of the subgenus Sternalixodes by undertaking phylogenetic analyses of morphological and molecular datasets.

Methods: Adult females ( $n=64$ ) of Sternalixodes, including Ixodes anatis Chilton, 1904, Ixodes confusus Roberts, 1960, Ixodes cornuatus Roberts, 1960, Ixodes cordifer Neumann, 1908, Ixodes dendrolagi Wilson, 1967, Ixodes hirsti Hassall, 1931, Ixodes holocyclus Neumann, 1899, Ixodes myrmecobii Roberts, 1962 and Ixodes trichosuri Roberts, 1960, were examined morphologically. Subsequently, these Ixodes spp. were genetically characterised using cytochrome $c$ oxidase subunit 1 (cox1) gene and the internal transcribed spacer 2 (ITS-2) of the rRNA. Both morphological and molecular datasets were analysed using various phylogenetic methods to assess the evolutionary relationship of various members of the subgenus Sternalixodes.
\end{abstract}

Results: Phylogenetic analyses of the cox 1 sequences and morphological characters datasets revealed that the Australian and Papuan Sternalixodes formed a distinct clade with the New Zealand member of the group I. anatis positioned basally, in a separate clade. Ixodes holocyclus, I. cornuatus and I. myrmecobii formed a distinctive clade in both the cox1 and morphological phylogenies. However, based on phylogenetic analysis of the ITS-2 data, I. holocyclus formed a separate clade whereas I. cornuatus and I. myrmecobii grouped in a different clade.

Conclusions: The cox 1 and morphological data suggest that the subgenus Sternalixodes is paraphyletic, and I. anatis is not a sternalixodid tick; hence, it should not be included in the subgenus. Based on the phylogenetic analyses of cox 1 and ITS-2 sequences, it appears that I. myrmecobii and I. cornuatus are not subspecies of I. holocyclus. Although this study provided better insights into the taxonomic status of the subgenus Sternalixodes, a complete morphological and molecular (using multiple markers) phylogenetic analysis including all members of the subgenus would be required to more accurately elucidate the evolutionary relationships within the subgenus.

Keywords: Ixodes, Sternalixodes, Phylogeny, Molecular, Morphological, Tick

\footnotetext{
* Correspondence: jabbara@unimelb.edu.au

${ }^{1}$ Department of Veterinary Biosciences, Melbourne Veterinary School, Faculty

of Veterinary and Agricultural Sciences, The University of Melbourne,

Werribee, Victoria 3030, Australia

Full list of author information is available at the end of the article
} 


\section{Background}

Ticks (Arachnida: Ixodidae) are important ectoparasites of humans and animals and can cause direct (e.g., paralysis, anaemia) as well as indirect (e.g., transmission of pathogens) effects on their hosts [1-3]. Ticks can be found on all continents and are known to feed on all types of terrestrial vertebrates, including mammals, birds, reptiles and amphibians [1,3]. The life-cycle of ixodid ticks consists of four developmental stages, the egg, and three active parasitic stages, larva, nymph, and adult (male and female). Depending on the type (hard, Ixodidae or soft, Argasidae) and species of ticks, their life-cycle can vary significantly.

To date, 70 species (56 and 14 members of families Ixodidae and Argasidae, respectively) of ticks have been recorded from a variety of hosts (humans and domestic animals $=16$; mammals, reptiles and birds $=54$ ) from Australia [4]. Among different genera of hard ticks prevalent in Australia, Ixodes is arguably the most important and its members are known to transmit and/ or harbour pathogens, including Rickettsia australis (the causative agent of Queensland tick typhus) in humans [5], and flaviviruses, bunyaviruses and Cercopithifilaria johnstoni Mackerras (Nematoda: Filarioidea) in wildlife [6-8]. Some Ixodes species such as I. holocyclus and I. cornuatus can also cause paralysis in humans, domestic animals, and wildlife [9]. Ixodes holocyclus is known to have an immunoeffectory action on humans, causing tick bite anaphylaxis [10].

Members of the genus Ixodes have not been intensively examined (e.g., phylogeny using combined morphological and molecular datasets, biology, life-cycle) within Australia. Few life-cycles have been elucidated and the bionomics of very few species are understood. Of the subgenera of Ixodes, Sternalixodes has received most attention. The subgenus comprises nine members, including Ixodes anatis, I. confusus, I. cornuatus, I. cordifer, I. dendrolagi, I. hirsti, I. holocyclus, I. myrmecobii and I. trichosuri [11]. However, the majority of studies have focussed on I. holocyclus and I. cornuatus, a species morphologically similar to I. holocyclus, aiming to determine their distribution $[1,12]$, morphological and molecular identification $[1,13]$ and phylogenetic relationships [14]. A number of questions therefore remain to be answered regarding the members of the subgenus Sternalixodes. For instance, the status of I. myrmecobii as subspecies of I. holocyclus as proposed by Roberts [1] needs to be tested. To date, Australian paralysis ticks and their relatives have not been analysed using morphological as well as molecular phylogenetics. Being an important subgenus, Sternalixodes requires systematic investigations to address a number of taxonomic questions regarding the validity of its members. Therefore, this study was designed to elucidate the evolutionary relationships of members of the subgenus Sternalixodes by undertaking phylogenetic analyses of morphological and molecular datasets.

\section{Methods}

Tick collection and morphological identification

Female ticks $(n=74)$ used in this study were either available from The University of Melbourne (Ian Beveridge and Abdul Jabbar) or museums in Australia (South Australian Museum, Western Australian Museum, and Australian National Insect Collection), New Zealand (A. Heath, AgResearch, New Zealand), Papua New Guinea (Ifor L. Owen, National Veterinary Laboratory, Papua New Guinea) and South America (A. Guglielmone, Instituto Nacional de Technologia Agropecuaria, Argentina) (Fig. 1; Table 1). Following collection, each tick specimen was stored in $70 \%$ ethanol until used. Developmental stages of all species of Sternalixodes could not be examined as many are not yet described.

For morphological identification, each tick was examined using a dissecting microscope (Olympus, Japan). In
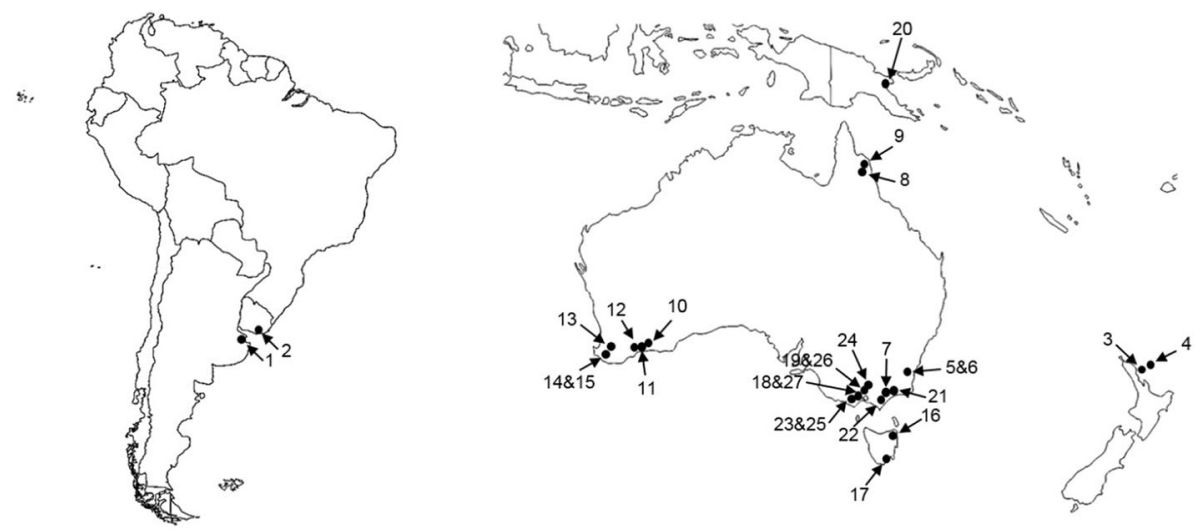

Fig. 1 Collection sites for Ixodes species from Argentina, Australia, New Zealand and Uruguay, used in this study. Information linked to each unique number on the map is provided in Table 1 
Table 1 Specimens of Ixodes spp. used in molecular studies, and their sources and collection sites

\begin{tabular}{|c|c|c|c|c|c|}
\hline Species & Specimen voucher & Locality & Hosts/collection method & Source & Map code \\
\hline \multirow[t]{2}{*}{ I. auritulus } & S63 & Buenos Aires, Argentina & Collected via flagging & A. Guglielmone & 1 \\
\hline & S64 & Rocha, Uruguay & Collected via flagging & A. Guglielmone & 2 \\
\hline \multirow[t]{2}{*}{ I. anatis } & S28 & Auckland Zoo, New Zealand & Apteryx mantelli & A. Heath & 3 \\
\hline & S29 & Ponui Island, New Zealand & Apteryx mantelli & A. Heath & 4 \\
\hline \multirow[t]{5}{*}{ I. holocyclus } & S1 & Kioloa, NSW, Australia & Collected via flagging & This study & 5 \\
\hline & S4 & Kioloa, NSW, Australia & Collected via flagging & This study & 6 \\
\hline & S37 & Waygara, Vic, Australia & Canis lupus familiaris & This study & 7 \\
\hline & S17 & Wandecla NP, QLD, Australia & Canis lupus familiaris & This study & 8 \\
\hline & S39 & Atherton, QLD, Australia & Canis lupus familiaris & This study & 9 \\
\hline \multirow[t]{6}{*}{ I. myrmecobii } & S26 & Cape Le Grand NP, WA, Australia & Unknown & WAM & 10 \\
\hline & S46 & Munglinup, WA, Australia & Homo sapiens & WAM & 11 \\
\hline & S56 & Quaalup Station, WA, Australia & Unknown & WAM & 12 \\
\hline & S44 & Cranbrook, WA, Australia & Homo sapiens & WAM & 13 \\
\hline & S25 & Stirling Ranges NP, WA, Australia & Unknown & WAM & 14 \\
\hline & S42 & Stirling Ranges NP, WA, Australia & Unknown & WAM & 15 \\
\hline \multirow[t]{4}{*}{ I. cornuatus } & S19 & Mt William NP, Tas, Australia & Vombatus ursinus & ANIC & 16 \\
\hline & S20 & Acton Park, Tas, Australia & Unknown & This study & 17 \\
\hline & S18 & Bullengarook, Vic, Australia & Canis lupus familiaris & ANIC & 18 \\
\hline & S41 & Kinglake, Vic, Australia & Canis lupus familiaris & This study & 19 \\
\hline I. dendrolagi & S14 & Gondom, Papua New Guinea & Dendrolagus matschiei & This study & 20 \\
\hline \multirow[t]{2}{*}{ I. trichosuri } & S23 & Bellbird Creek, Vic, Australia & Trichosurus caninus & ANIC & 21 \\
\hline & S21 & Nowa Nowa, Vic, Australia & Unknown & ANIC & 22 \\
\hline \multirow[t]{3}{*}{ 1. hirsti } & S10 & Anglesea, Vic, Australia & Macropus giganteus & This study & 23 \\
\hline & S12 & Mansfield, Vic, Australia & Felis catus & ANIC & 24 \\
\hline & S9 & Anglesea, Vic, Australia & Macropus giganteus & This study & 25 \\
\hline \multirow[t]{2}{*}{ 1. tasmani } & S68 & Kinglake, Vic, Australia & Unknown & This study & 26 \\
\hline & S69 & Bullengarook, Vic, Australia & Unknown & This study & 27 \\
\hline
\end{tabular}

Abbreviations: ANIC Australian National Insect Collection, NSW New South Wales, QLD Queensland, NP National Park, Tas Tasmania, WA Western Australia, WAM Western Australia Museum, Vic Victoria

addition, electron micrographs were taken using a Hitachi TM3030 Tabletop Scanning Electron Microscope, Germany. All Australian and Papuan tick species were identified using keys by Roberts [1]; whereas I. anatis specimens were identified following Hardwick [15] and $I$. auritulus Neumann, 1904 specimens were identified by A. Heath and A. Guglielmone.

One or two legs were removed from each specimen using flame sterilized forceps and stored in $70 \%$ ethanol for molecular work.

\section{DNA extraction, PCR amplification and DNA sequencing}

Prior to DNA extraction, ethanol was removed and $\operatorname{leg}(\mathrm{s})$ of individual ticks were washed three times (30 min) in distilled $\mathrm{H}_{2} \mathrm{O}$, and then ground using a plastic mortar. DNA was extracted using a DNeasy Blood and Tissue Kit (Qiagen, Hilden, Germany) following the protocol provided by the manufacturer.
Two loci (one mitochondrial and one nuclear ribosomal DNA) were PCR-amplified separately from each individual genomic DNA sample. The first locus (partial cox 1 gene, $\sim 850 \mathrm{bp}$ ) was amplified using the primers $\mathrm{HCO} 2064$ (5'-GGT GGG CTC ATA CAA TAA ATC C-3') and HCOX1215 (5'-GCC ATT TTA CCG CGA TGA-3'); the second locus (partial second internal transcribed spacer, ITS-2; 760 bp) was amplified employing primers ITS865 (5'-CTC GCC TGA TCG TGA GGT CG-3') and ITS105 (5'-GGT CGA ATT GCC CCT CCT CG-3') [14]. All PCRs were performed in a final volume of $50 \mu \mathrm{l}$, containing $10 \mathrm{mM}$ Tris- $\mathrm{HCl}$ (pH 8.4), $50 \mathrm{mM} \mathrm{KCl}, 3.5 \mathrm{mM}$ of $\mathrm{MgCl}_{2}$, $200 \mu \mathrm{M}$ of deoxynucleotide triphosphate, $100 \mathrm{pmol}$ of each primer and $1 \mathrm{U}$ of GoTaq polymerase (Promega, Madison, WI, USA) under the following cycling conditions: $94{ }^{\circ} \mathrm{C}$ for 5 min (initial denaturation); 35 cycles of $94{ }^{\circ} \mathrm{C}$ for $30 \mathrm{~s}$ (extension), $48{ }^{\circ} \mathrm{C}(\operatorname{cox} 1)$ or $50{ }^{\circ} \mathrm{C}$ (ITS-2) for $30 \mathrm{~s}$ (annealing) and $72{ }^{\circ} \mathrm{C}$ for $50 \mathrm{~s}$ (extension), followed by final extension 
Table 2 List of morphological characters (character numbers, name of character, character states)

\begin{tabular}{|c|c|c|c|c|c|}
\hline \multirow[t]{2}{*}{ No. } & \multirow[t]{2}{*}{ Feature or structure } & \multicolumn{4}{|l|}{ Character states } \\
\hline & & 0 & 1 & 2 & 3 \\
\hline 1. & Hypostome - 1 & lanceolate & spatulate & & \\
\hline 2. & Hypostome - 2 & blunt & bluntly-pointed & acutely pointed & \\
\hline 3. & Hypostome - 3 & Not bilobed & bilobed & & \\
\hline 4. & Dentition - 1 & 3/3 apically & 4/4 apically & 5/5 apically & \\
\hline 5. & Dentition - 2 & only $3 / 3$ mid-hypostome & 4/4 and 3/3 mid-hypostome & & \\
\hline 6. & Dentition - 3 & $2 / 2$ basally & 3/3 basally (1) & & \\
\hline 7. & Palpal article 1-1 & $\begin{array}{l}\text { does not ensheath } \\
\text { mouthparts }\end{array}$ & $\begin{array}{l}\text { ensheathes basal portion } \\
\text { of mouthparts }\end{array}$ & & \\
\hline 8. & Palpal article 1-2 & $\begin{array}{l}\text { no internal horn-like } \\
\text { projection }\end{array}$ & internal horn-like projection & & \\
\hline 9. & Palpal article 1-3 & rounded dorsally & rectangular dorsally & sub-rectangular dorsally & triangular dorsally \\
\hline 10. & Palpal articles 2 and 3-1 & separate & faint suture present & between articles & fused \\
\hline 11. & Palpal articles 2 and 3-2 & short and broad & long and slender & & \\
\hline 12. & Palpal article 2 and 3-3 & distal spur absent & distal spur present & & \\
\hline 13. & Auriculae & absent & present & & \\
\hline 14. & Cornua & absent & present & & \\
\hline 15. & $\begin{array}{l}\text { Ventral posterior lobe on } \\
\text { basis capituli }\end{array}$ & absent & present & & \\
\hline 16. & Porose areas & $\begin{array}{l}\text { separated by equal to or } \\
\text { less than half their width }\end{array}$ & $\begin{array}{l}\text { separated by more than } \\
\text { half their width }\end{array}$ & & \\
\hline 17. & $\begin{array}{l}\text { Median depression between } \\
\text { porose areas }\end{array}$ & present & absent & & \\
\hline 18. & $\begin{array}{l}\text { Dorsal lateral carina(e) on } \\
\text { basis capituli - } 2\end{array}$ & absent & $\begin{array}{l}\text { not extending to base } \\
\text { of hypostome }\end{array}$ & $\begin{array}{l}\text { extending to base } \\
\text { of hypostome }\end{array}$ & \\
\hline 19. & $\begin{array}{l}\text { Dorsal carinae on basis } \\
\text { capituli }\end{array}$ & median carina present & median carina absent & & \\
\hline 20. & $\begin{array}{l}\text { Ventral lateral carinae on } \\
\text { basis capituli - } 2\end{array}$ & absent & $\begin{array}{l}\text { not extending to base } \\
\text { of hypostome }\end{array}$ & $\begin{array}{l}\text { extending to base } \\
\text { of hypostome }\end{array}$ & \\
\hline 21. & $\begin{array}{l}\text { Ventral carinae on basis } \\
\text { capituli - } 3\end{array}$ & no carinae & two carinae & three carinae & \\
\hline 22. & Scutum - 1 & longer than wide & wider than long & as long as wide & \\
\hline 23. & Scutum - 2 & lateral carinae absent & lateral carinae present & & \\
\hline 24. & Scutum - 3 & $\begin{array}{l}\text { cervical grooves extending } \\
\text { less than halfway down } \\
\text { scutum }\end{array}$ & $\begin{array}{l}\text { cervical grooves extending } \\
\text { halfway or more down } \\
\text { scutum }\end{array}$ & & \\
\hline 25. & Scutum - 4 & emarginations absent & emarginations present & & \\
\hline 26. & Scapulae & absent & present & & \\
\hline 27. & Sternal plate - (0), (1) & absent & present & & \\
\hline 28. & Genital aperture & $\begin{array}{l}\text { level with third intercoxal } \\
\text { space }\end{array}$ & $\begin{array}{l}\text { level with mid-fourth } \\
\text { intercoxal space }\end{array}$ & & \\
\hline 29. & Coxae I & external spur present & external spur absent & & \\
\hline 30. & Coxae II & external spur present & external spur absent & & \\
\hline 31. & Coxae III & external spur present & external spur absent & & \\
\hline 32. & Coxae IV & external spur present & external spur absent & & \\
\hline 33. & Syncoxae & Present & Absent & & \\
\hline 34. & Ridges/rugosities - 1 & absent on coxa I & present on coxa I & & \\
\hline
\end{tabular}


Table $\mathbf{2}$ List of morphological characters (character numbers, name of character, character states) (Continued)

\begin{tabular}{llll}
\hline 35. & Ridges/rugosities - 2 & absent on coxa II & present on coxa II \\
36. & Ridges/rugosities - 3 & absent on coxa III & present on coxa III \\
37. & Ridges/rugosities - 4 & absent on coxa IV & present on coxa IV \\
38. & Anal groove & does not meet posteriorly & meets posteriorly \\
\hline
\end{tabular}

at $72{ }^{\circ} \mathrm{C}$ for $5 \mathrm{~min}$. For each set of PCRs, negative (noDNA) and positive (I. holocyclus DNA) controls were included. No amplification was detected in any of the negative control reactions at any time during the study. Amplicons $(5 \mu \mathrm{l})$ were examined on $1.5 \%$ agarose gels stained with ethidium bromide. Gels were examined using transillumination and were photographed using a GelDoc system (BioRad, Hercules, CA, USA). If amplicons were not detected on agarose gel, then semi-nested PCRs were used as follows: HCOX1240 (5'-CCA CAA ATC ATA AAG ACA TTG G-3') was used in conjunction with HCO2064 to amplify cox1 and ITS130 (5'-AGT TGT ACA TTG G-3') in conjunction with ITS865 was used to amplify ITS-2. PCR cycling conditions for semi-nested PCRs were same as used above.

For each locus, amplicon(s) representing each Ixodes species were purified using shrimp alkaline phosphatase and exonuclease 1 [16] prior to automated DNA sequencing (ABI3730XL automatic sequencer at Macrogen Cooperation, South Korea). Sequencing of the $\operatorname{cox} 1$ and ITS-2 region was conducted using the primers $\mathrm{HCO} 2064$ and HCOX1215 or HCO2064 and HCOX1240 (cox1) and ITS865 and ITS105 or ITS865 and ITS130 (ITS-2), in separate reactions. The quality of each sequence obtained was appraised using the program Geneious Pro 6.5 (Biomatters Ltd., Auckland, New Zealand) [17]. Partial cox1 sequences were identified by local alignment comparison (set reading frames) using amino acid sequences conceptually translated using an online tool http://www.ebi.ac.uk/Tools/st/emboss_transeq/ from the respective loci of the reference sequence of $I$. holocyclus are available from GenBank.

\section{Phylogenetic analyses}

For morphological phylogenetics, the character matrix was based on adult female specimens. All characters are morphological, collected by examining specimens using light and/or scanning electron microscopy. Characters that could not be scored with complete accuracy in some taxa were excluded from the analysis. Morphological data were analysed employing Maximum Parsimony (MP) in TnT [18], gaps were treated as missing characters, and bootstrap replicates and maximum trees were set at 10,000. In addition, data were analysed using Bayesian Inference (BI) by employing the Markov K model in MrBayes 3.2.6 [19-21]. Lset rates were set to gamma and coding was set to variable. Four simultaneous tree-building chains were used to calculate posterior probabilities (pp) for 2,000,000 generations, saving every 100th tree produced. Based on the final $75 \%$ of trees generated, a consensus tree was constructed. Ixodes tasmani Neumann, 1899 was used as the outgroup.

For molecular phylogenetics, nucleotide sequences were aligned using the MUSCLE V 3.8.31 program [22] and adjusted manually employing the program Mesquite V 3.03 [23]. Based on pairwise comparisons, sequence differences were calculated using the program MEGA 6.0. [24]. Two separate datasets representing $\operatorname{cox} 1$ and ITS-2 were compiled, together with reference sequences from GenBank [14, 25, 26]; I. tasmani and I. uriae White, 1852 were used as the outgroups, respectively. Both cox 1 and ITS-2 sequences were aligned over 519 and $610 \mathrm{bp}$, respectively, and adjusted manually as described above. Phylogenetic analyses were performed on individual $\operatorname{cox} 1$ and ITS-2 datasets using Maximum Likelihood (ML), Neighbour-Joining (NJ) and BI methods. The ML and NJ analyses were performed using MEGA 6.0. and the nodes were tested for robustness with 10,000 bootstrap replicates. The data format was set to DNA and gaps were treated as missing data $(10,000$ bootstrap replicates, Max. trees was set at 10,000). The likelihood parameters for the BI (TIM2+I $+\mathrm{G}$ for $\mathrm{pCXO} 1$ and $\mathrm{TVM}+\mathrm{G}$ for ITS-2) and ML (Tamura 3-parameter model for both cox1 and ITS-2) analyses were selected based on the Akaike Information Criterion (AIC) test in jModeltest v2.1.5 [27]. The BI was conducted, using Monte Carlo Markov Chain (MCMC) analysis in MrBayes 3.1.2. Four simultaneous tree-building chains were used to calculate posterior probabilities (pp) for 2,000,000 generations, saving every 100 th tree produced. Based on the final $75 \%$ of trees generated, a consensus tree was constructed.

The phylogenetic trees produced for both morphological and molecular datasets were visually compared separately for concordance in their topologies.

\section{Results}

\section{Morphological characterisation}

Out of 74 individual specimens of female Ixodes examined, 64 belonged to the subgenus Sternalixodes, including $I$. anatis $(n=7)$, I. dendrolagi $(n=3)$, I. cordifer $(n=5), I$. cornuatus $(n=5), I$. hirsti $(n=10), I$. holocyclus $(n=13)$, I. myrmecobii $(n=17)$ and I. trichosuri $(n=4)$; 
Table 3 Morphological character matrix of character states for each taxon used to construct morphological phylogeny

\begin{tabular}{lllllllllllllllllllllllllllllllllllllllllll}
\hline Species/State & 1 & & & & & & & & & & & & & 1 & 1 & 1 & 1 & 1 & 1 & 1 & 1 & 1 & 1 & 2 & 2 & 2 & 2 & 2 & 2 & 2 & 2 & 2 & 2 & 3 & 3 & 3 & 3 & 3 & 3 & 3 & 3 & 3 \\
\hline I. auritulus & 0 & 0 & 0 & 2 & 1 & 1 & 0 & 1 & 3 & 1 & 1 & 0 & 1 & 1 & 0 & 0 & 0 & 0 & 0 & 0 & 0 & 0 & 0 & 1 & 0 & 0 & 0 & 0 & 1 & 1 & 1 & 1 & 0 & 0 & 0 & 0 & 0 & 0 \\
I. anatis & 0 & 0 & 1 & 0 & 0 & 0 & 0 & 0 & 1 & 0 & 1 & 1 & 1 & 0 & 1 & 0 & 0 & 0 & 0 & 0 & 0 & 1 & 0 & 1 & 0 & 0 & 0 & 0 & 1 & 0 & 0 & 0 & 0 & 0 & 0 & 0 & 0 & 0 \\
I. tasmani & 1 & 0 & 0 & 1 & 0 & 0 & 1 & 0 & 1 & 0 & 0 & 0 & 0 & 0 & 0 & 1 & 1 & 0 & 0 & 0 & 0 & 1 & 0 & 1 & 1 & 1 & 0 & 0 & 0 & 0 & 0 & 0 & 1 & 0 & 0 & 0 & 0 & 0 \\
I. holocyclus & 0 & 1 & 0 & 0 & 0 & 0 & 0 & 0 & 0 & 0 & 1 & 0 & 1 & 0 & 0 & 1 & 1 & 1 & 0 & 0 & 0 & 2 & 1 & 0 & 1 & 1 & 0 & 1 & 1 & 1 & 1 & 1 & 0 & 0 & 0 & 0 & 0 & 0 \\
I. cornuatus & 0 & 1 & 0 & 0 & 0 & 0 & 0 & 0 & 0 & 0 & 1 & 0 & 1 & 01 & 0 & 0 & 1 & 0 & 0 & 0 & 0 & 0 & 1 & 1 & 1 & 1 & 0 & 1 & 1 & 1 & 1 & 1 & 0 & 0 & 0 & 0 & 0 & 1 \\
I. myrmecobii & 0 & 1 & 0 & 0 & 0 & 0 & 0 & 0 & 0 & 0 & 1 & 0 & 1 & 1 & 0 & 1 & 1 & 1 & 0 & 1 & 1 & 0 & 1 & 0 & 1 & 1 & 0 & 0 & 1 & 1 & 1 & 1 & 0 & 0 & 0 & 0 & 0 & 1 \\
I. cordifer & 0 & 2 & 0 & 0 & 0 & 0 & 0 & 0 & 0 & 0 & 1 & 0 & 1 & 0 & 0 & 0 & 0 & 0 & 0 & 0 & 0 & 0 & 1 & 0 & 0 & 1 & 1 & 1 & 1 & 1 & 1 & 1 & 0 & 0 & 0 & 0 & 0 & 1 \\
I. dendrolagi & 0 & 2 & 0 & 0 & 0 & 0 & 0 & 0 & 0 & 0 & 1 & 0 & 1 & 0 & 0 & 0 & 0 & 1 & 1 & 1 & 1 & 0 & 1 & 1 & 0 & 1 & 1 & 1 & 1 & 1 & 1 & 1 & 0 & 1 & 1 & 1 & 0 & 1 \\
I. confusus & 0 & 2 & 0 & 0 & 0 & 0 & 0 & 0 & 0 & 0 & 1 & 0 & 1 & 0 & 0 & 0 & 0 & 2 & 1 & 2 & 2 & 0 & 1 & 1 & 1 & 1 & 1 & 1 & 1 & 1 & 1 & 1 & 0 & 1 & 1 & 1 & 1 & 1 \\
I. hirsti & 0 & 2 & 0 & 0 & 0 & 0 & 0 & 0 & 0 & 0 & 1 & 0 & 1 & 0 & 0 & 0 & 1 & 2 & 0 & 2 & 1 & 0 & 1 & 0 & 1 & 1 & 1 & 1 & 1 & 1 & 1 & 1 & 0 & 1 & 1 & 0 & 0 & 1 \\
I. trichosuri & 0 & 2 & 0 & 0 & 0 & 0 & 0 & 0 & 0 & 0 & 1 & 0 & 1 & 0 & 0 & 0 & 1 & 2 & 0 & 2 & 1 & 0 & 1 & 0 & 1 & 1 & 1 & 1 & 1 & 1 & 1 & 1 & 0 & 0 & 0 & 0 & 0 & 1 \\
\hline
\end{tabular}

whereas, remaining 10 belonged to two subgenera Endopalpiger Schulze (I. tasmani; $n=6)$ and Multidentatus Neumann (I. auritulus; $n=4)$.

Character states are presented in Table 2, and the morphological data matrix is provided in Table 3. In addition, principal features of the capitulum used as characters are shown in Fig. 2.

\section{Molecular characterisation}

PCR amplification was successful for 27 (out of 64) genomic DNA samples extracted from individual tick specimens (Table 1). Considerable variation in the size
( 650 to $750 \mathrm{bp})$ of amplicons $(n=15)$ for the ITS-2 was detected on agarose gel, whereas the amplicon size ( $700 \mathrm{bp})$ for $\operatorname{cox} 1(n=27)$ did not differ. DNA sequencing of amplicons for both loci revealed 27 and 15 unique sequences for $\operatorname{cox} 1$ and ITS-2, respectively. Sequence length, $\mathrm{G}+\mathrm{C}$ content, pairwise differences and GenBank accession numbers for cox1 (KY213767KY213793) and ITS-2 (KY213752-KY213766) sequences are given in Table 4. The length of $\operatorname{cox} 1$ sequences for each tick species was $674 \mathrm{bp}$, whereas that of ITS-2 ranged from 630 to $704 \mathrm{bp}$. Among various members of Sternalixodes, the highest genetic variation was detected

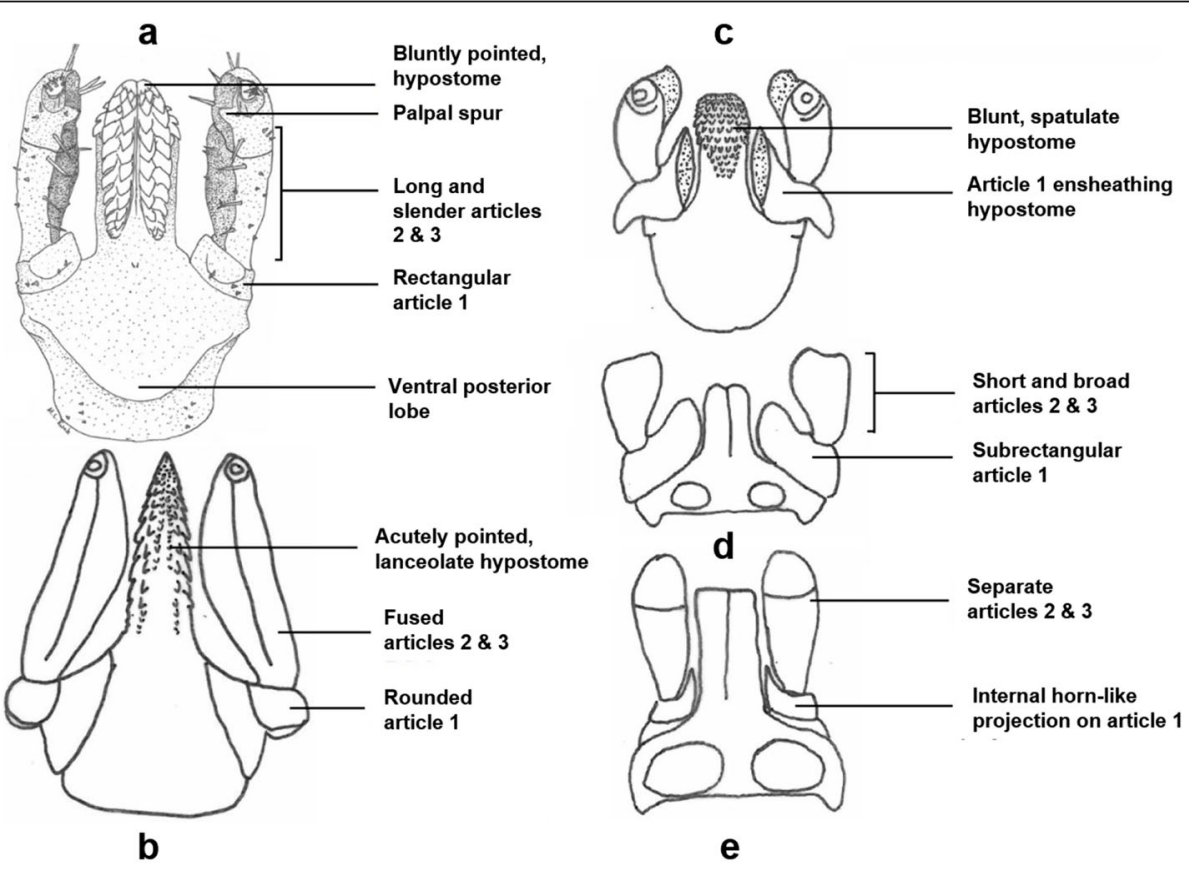

Fig. 2 Principal features of the capitulum used as characters in Table 2. Capituli of a, Ixodes cornuatus (ventral view); b, Ixodes hirsti (ventral view); c, Ixodes tasmani (ventral view); d, Ixodes tasmani (dorsal view), and e, Ixodes auritulus (dorsal view) 
Table 4 Characteristics of sequences of Ixodes species determined in this study. GenBank accession numbers, G+C content and length of each sequence, and pairwise differences for each species with more than one specimens are provided

\begin{tabular}{|c|c|c|c|c|c|c|c|c|c|}
\hline \multirow[t]{2}{*}{ Species } & \multirow{2}{*}{$\begin{array}{l}\text { Specimen } \\
\text { voucher }\end{array}$} & \multicolumn{4}{|l|}{$\operatorname{cox} 1^{a}$} & \multicolumn{4}{|l|}{ ITS-2 $2^{b}$} \\
\hline & & $\begin{array}{l}\text { GenBank } \\
\text { accession no. }\end{array}$ & $\begin{array}{l}\text { Length } \\
\text { (bp) }\end{array}$ & $\begin{array}{l}\mathrm{G}+\mathrm{C} \\
\text { content (\%) }\end{array}$ & $\begin{array}{l}\text { Pairwise } \\
\text { difference (\%) }\end{array}$ & $\begin{array}{l}\text { GenBank } \\
\text { accession no. }\end{array}$ & $\begin{array}{l}\text { Length } \\
\text { (bp) }\end{array}$ & $\begin{array}{l}\mathrm{G}+\mathrm{C} \\
\text { content (\%) }\end{array}$ & $\begin{array}{l}\text { Pairwise } \\
\text { difference (\%) }\end{array}$ \\
\hline \multirow[t]{2}{*}{ 1. auritulus } & 563 & KY213767 & 674 & 31.75 & 1.1 & - & - & - & - \\
\hline & S64 & KY213768 & 674 & 31.75 & & - & - & - & - \\
\hline \multirow[t]{2}{*}{ 1. anatis } & $\mathbf{S} 28$ & KY213769 & 674 & 31.90 & 1.2 & KY213757 & 703 & 54.62 & - \\
\hline & S29 & KY213770 & 674 & 31.90 & & - & - & - & - \\
\hline \multirow[t]{5}{*}{ I. holocyclus } & S1 & KY213782 & 674 & 32.20 & $0.2-0.9$ & KY213766 & 679 & 55.38 & $1.4-8.6$ \\
\hline & S4 & KY213783 & 674 & 32.05 & & KY213765 & 630 & 55.70 & \\
\hline & S37 & KY213781 & 674 & 32.34 & & KY213756 & 684 & 55.40 & \\
\hline & S17 & KY213779 & 674 & 32.49 & & KY213762 & 638 & 55.80 & \\
\hline & S39 & KY213780 & 674 & 31.90 & & KY213755 & 676 & 55.47 & \\
\hline \multirow[t]{6}{*}{ I. myrmecobii } & S26 & KY213784 & 674 & 30.86 & $0.2-1.1$ & KY213758 & 649 & 53.80 & $0.8-3.6$ \\
\hline & S46 & KY213785 & 674 & 31.16 & & KY213753 & 656 & 53.70 & \\
\hline & S56 & KY213786 & 674 & 31.00 & & KY213752 & 657 & 53.60 & \\
\hline & S44 & KY213787 & 674 & 31.00 & & - & - & - & \\
\hline & S25 & KY213788 & 674 & 30.70 & & KY213759 & 668 & 53.30 & \\
\hline & $\$ 42$ & KY213789 & 674 & 30.86 & & KY213754 & 647 & 53.80 & \\
\hline \multirow[t]{4}{*}{ I. cornuatus } & S19 & KY213792 & 674 & 30.42 & $0.2-1.2$ & - & - & - & - \\
\hline & $\mathrm{S} 20$ & KY213793 & 674 & 30.12 & & - & - & - & - \\
\hline & $\mathrm{S} 18$ & KY213790 & 674 & 30.12 & & KY213761 & 654 & 53.36 & - \\
\hline & S41 & KY213791 & 674 & 30.27 & & - & - & - & - \\
\hline I. dendrolagi & S14 & KY213776 & 674 & 30.70 & - & KY213763 & 672 & 55.20 & - \\
\hline \multirow[t]{2}{*}{ I. trichosuri } & $\mathbf{S} 23$ & KY213777 & 674 & 31.90 & 0.3 & - & - & - & - \\
\hline & $\mathrm{S} 21$ & KY213778 & 674 & 31.90 & & KY213760 & 704 & 56.39 & - \\
\hline \multirow[t]{3}{*}{ I. hirsti } & $\mathrm{S} 10$ & KY213773 & 674 & 33.10 & $0.2-0.3$ & - & - & - & - \\
\hline & $\mathrm{S} 12$ & KY213774 & 674 & 33.38 & & - & - & - & - \\
\hline & S9 & KY213775 & 674 & 33.23 & & KY213764 & 667 & 56.97 & - \\
\hline \multirow[t]{2}{*}{ I. tasmani } & S68 & KY213771 & 674 & 32.20 & 10.9 & - & - & - & - \\
\hline & 569 & KY213772 & 674 & 32.05 & & - & - & - & - \\
\hline
\end{tabular}

${ }^{a} \operatorname{cox} 1$ : cytochrome $c$ oxidase subunit $1{ }^{\mathrm{b}} \mathrm{ITS}-2$ : second internal transcribed spacer

in $I$. cornuatus (number of sequences $=4$; pairwise differences $0.2-12 \%)$ followed by $I$. anatis $(n=2 ; 1.2 \%), I$. myrmecobii ( $n=6 ; 0.2-1.1 \%)$, I. auritulus $(n=2 ; 1.1 \%)$, . holocyclus $(n=5 ; 0.2-0.9 \%), I$. hirsti $(n=3 ; 0.2-0.3 \%)$ and $I$. trichosuri $(n=2 ; 0.3 \%)$ (Table 4$)$. Based on ITS-2 sequences, multiple sequences for individual ticks were obtained only for I. holocyclus and I. myrmecobii and their pairwise differences were $1.4-8.6 \%$ and $0.8-3.6 \%$, respectively (Table 4 ).

\section{Phylogenetic analyses}

The topology of the phylogenetic trees generated for morphological data employing $\mathrm{BI}$ and $\mathrm{MP}$ methods were similar (data not shown); hence, the MP tree is presented here, with nodal support values given for both methods (Fig. 3). The morphological phylogram showed six main clades, clade numbers including taxa of the preceding clade. Ixodes confusus and I. dendrolagi grouped together in clade 1, with moderate statistical support (posterior probability for BI: 0.99; bootstrap value for MP: 87\%) (Fig. 3). Ixodes hirsti, I. trichosuri, I. auritulus and $I$. anatis each formed a clade (2, 3, 5 and 6, respectively), with no to high statistical support (Fig. 3). The common Australian paralysis tick, I. holocyclus, and I. cordifer, I. cornuatus and I. myrmecobii formed clade 4, with low to moderate statistical support $(0.92,79 \%)$.

Molecular phylogenetic analyses revealed that the topology of trees generated from the cox1 (aligned over 519 positions) and ITS-2 (608 positions) sequence data were similar using BI, NJ and ML (data not shown); hence, only the NJ trees for both loci are presented here (Figs. 4 


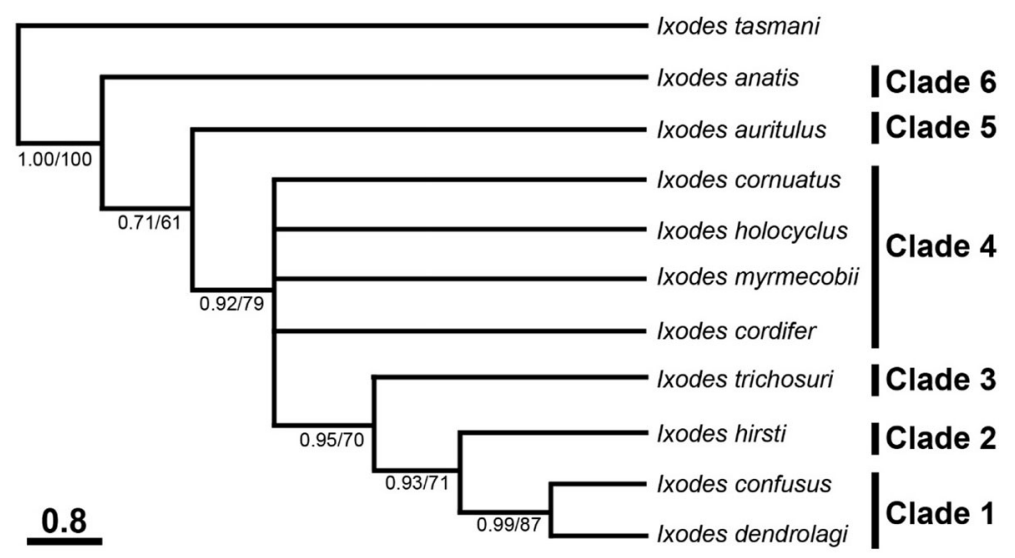

Fig. 3 Morphological phylogram of specimens of Sternalixodes from Argentina, Australia, New Zealand and Uruguay. The relationships were inferred based on 38 morphological characters using Maximum Parsimony (MP) and Bayesian Inference (BI) methods. Ixodes tasmani was used as the outgroup. There was a concordance in the topology between this MP tree and that produced using BI (not shown). Nodal support (from left to right) is given as a posterior probability for BI and bootstrap values for MP. For simplicity, each clade number includes taxa in the preceding clade. The scale-bar indicates the number of inferred substitutions per character

and 5). The cox 1 tree had three major clades (Fig. 4) in which I. cornuatus, I. holocyclus and I. myrmecobii formed Clade 1, with mixed statistical support (posterior probability for BI: 0.90; bootstrap value for NJ and ML: 97 and 86\%). Individually, five cox1 sequences of $I$. holocyclus determined herein (GenBank accession nos. KY213779-KY213782) grouped together with those previously published from Australia, with strong statistical support $(0.99,100,99 \%)$ (Fig. 4). All six cox 1 sequences of $I$. myrmecobii grouped together with strong statistical support $(0.99,100,96 \%)$, whereas four $\operatorname{cox} 1$ sequences of I. cornuatus found in this study formed two sub-clades with strong statistical support $(1.0,100,99 \%)$ in which two sequences from Tasmania (KY213792 and KY213793) grouped outside the other two sequences from this study (KY213790 and KY213791) as well as previously published sequences (Fig. 4). Clade 2 contained I. dendrolagi, I. hirsti and I. trichosuri but without statistical support (0.68, 58, 51\%; Fig. 4). However, individual sequences of $I$. hirsti determined here (KY213773-KY213775) formed a separate sub-clade compared with previously published sequences of this species. Ixodes auritulus and I. anatis formed Clade 3 with weak to moderate statistical support $(0.98,67,70 \%)$ (Fig. 4).

The ITS-2 tree contained four major clades (Fig. 5). However, the composition of some clades was different from that found in the cox 1 tree. For example, in the ITS- 2 tree, Clade 1 contained only $I$. holocyclus with strong statistical support $(1.0,100,99 \%)$ whereas $I$. cornuatus and I. myrmecobii formed a separate clade (Clade 3) with strong statistical support (1.0, 100, 99\%) (Fig. 5). Similarly in the cox 1 tree, I. dendrolagi, I. hirsti and I. trichosuri formed a separate clade (Clade 2) with strong statistical support (1.0, 99, 95\%) whereas I. anatis formed a separate clade outside Australian and Papuan Ixodes spp. (Fig. 5).

\section{Discussion}

This study addressed the evolutionary relationships amongst the species of Sternalixodes, using both morphological and molecular phylogenetic methods. The cox 1 and morphological data suggest that the subgenus is paraphyletic with $I$. anatis which is congruent with a previous suggestion by Heath [28].

The topology was similar in the cox 1 and morphological trees, with the Australian and Papuan Sternalixodes forming a distinct clade and the New Zealand member of the group I. anatis positioned basally, in a separate clade. Ixodes holocyclus, I. cornuatus and I. myrmecobii formed a distinctive clade in both the cox 1 and morphological phylogenies. This pattern supports comments made by Roberts [1], who suggested that these three species were closely related and that $I$. myrmecobii and I. cornuatus may be subspecies of $I$. holocyclus. Ixodes hirsti, I. trichosuri and I. dendrolagi formed a separate clade distinct from the I. holocyclus species group. It is possible that the resulting tree would show I. dendrolagi forming a distinct clade with these northern species rather than grouping with $I$. hirsti. The cox 1 phylogeny suggests that the outgroup I. tasmani contains a cryptic species based on the long branch lengths of the two I. tasmani samples (see Fig. 4) as previously proposed by Roberts [1].

While the morphological and cox 1 trees showed similar topologies, there were some differences. The position of $I$. auritulus was different between the cox 1 tree and the morphological tree, while I. auritulus and I. anatis 


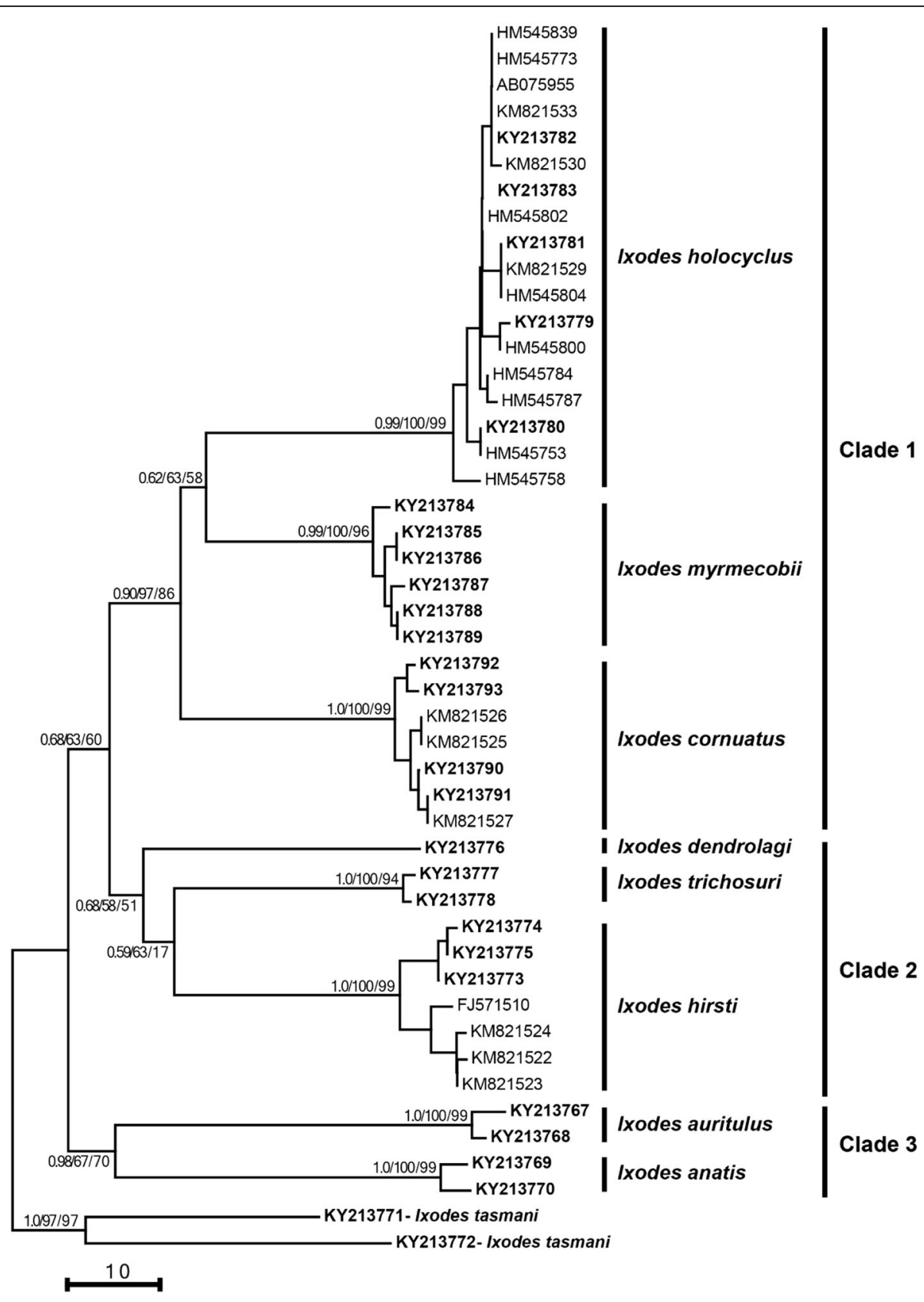

Fig. 4 Genetic relationships of specimens of Sternalixodes from Argentina, Australia, New Zealand and Uruguay. The relationships were inferred based on phylogenetic analyses of the cytochrome c oxidase subunit 1 (cox1) sequence data determined herein (bold) using Bayesian Inference (Bl), distance-based Neighbor Joining (NJ) and Maximum Likelihood (ML) methods. Previously published sequences of Ixodes species were obtained from GenBank (see accession numbers). Ixodes tasmani was used as the outgroup. There was a concordance in the topology between this NJ tree and those produced using Bl and ML (not shown). Nodal support (from left to right) is given as a posterior probability for Bl and bootstrap values for NJ and $\mathrm{ML}$. The scale-bar indicates the number of inferred substitutions per nucleotide site

formed a distinct clade in the cox 1 phylogram. However, in the morphological tree I. auritulus formed a clade with the Australian/Papuan Sternalixodes. It is likely that the groups are only distantly related as $I$. anatis, $I$. auritulus and the Australian Sternalixodes are all morphologically and molecularly distinct. More extensive morphological and molecular phylogenetic analyses are required to adequately illuminate the evolutionary relationships between the three groups. This would require more extensive morphological character sets as well as the use of other molecular markers such as $16 \mathrm{~S}$, $28 \mathrm{~S}$ or complete mitochondrial genomes.

Topological differences were also present between the two molecularly derived trees (see Figs. 4 and 5). The 


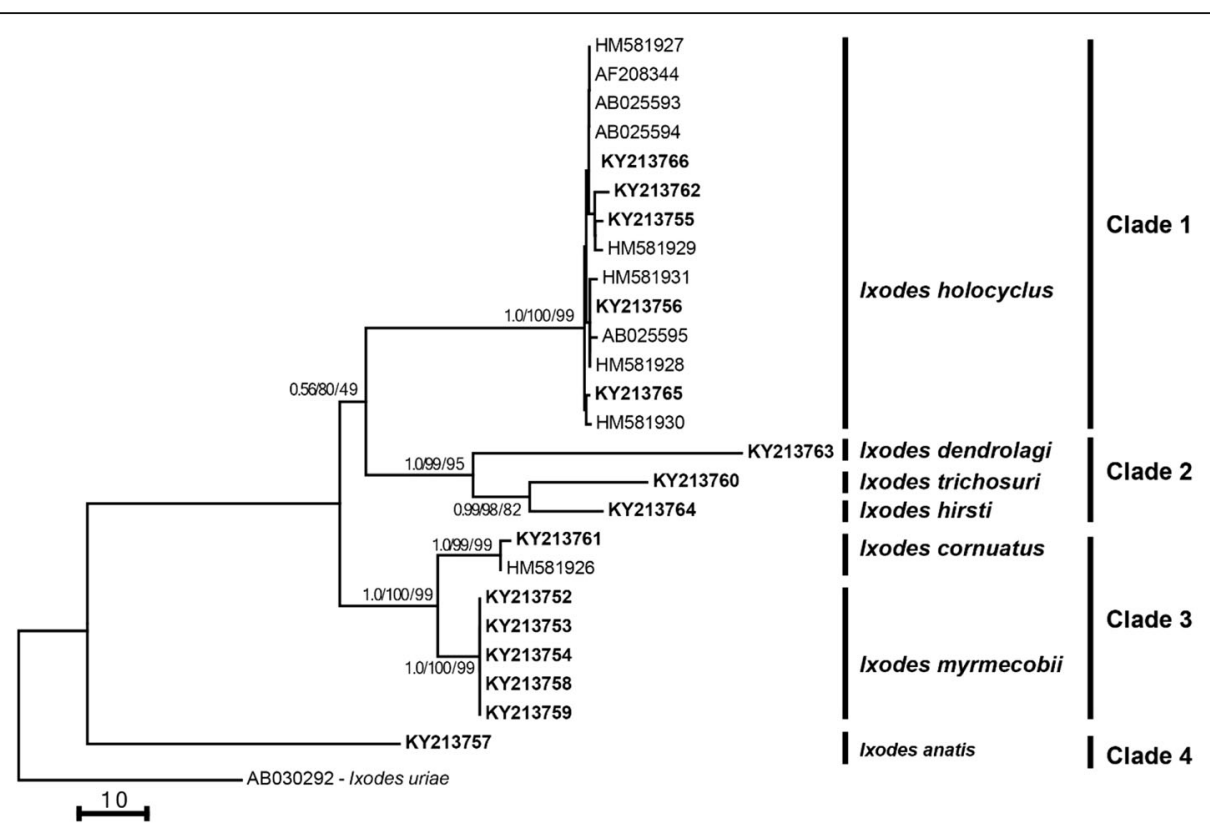

Fig. 5 Genetic relationships of specimens of Sternalixodes from Argentina, Australia, New Zealand and Uruguay. The relationships were inferred based on phylogenetic analyses of the second internal transcribed spacer (ITS-2) sequence data determined herein (bold) using Bayesian Inference (BI), distance-based Neighbor Joining (NJ) and Maximum Likelihood (ML) methods. Previously published sequences of Ixodes species were obtained from GenBank (see accession numbers). Ixodes uriae was used as the outgroup. There was a concordance in the topology between this NJ tree and those produced using Bl and ML (not shown). Nodal support (from left to right) is given as a posterior probability for Bl and bootstrap values for NJ and ML. The scale-bar indicates the number of inferred substitutions per nucleotide site

members of the I. holocyclus species group did not form a distinct clade in the ITS- 2 tree as was seen in the cox 1 tree, but instead formed two separate clades comprising I. cornuatus and I. myrmecobii in one and I. holocyclus in the other. The morphologically similar species, $I$. holocyclus and I. cornuatus grouped in highly divergent clades contrary to morphological evidence, as well as inferences from previous study of the interspecific relationship of these species by Song et al. [14]. This was likely due to the conserved nature of this marker in ticks. Song et al. [14] commented on the conserved nature of ITS-2 in Sternalixodes noting that intraspecific variation between I. holocyclus and I. cornuatus was as low as $0.19 \%$. Despite suggestions that ITS-2 is suitable for inferring evolutionary relationships in ticks [14], it appears that it may not be suited for revealing the relationships between more distantly related species within subgenera.

Within the cox 1 phylogeny, I. hirsti was divided into two distinct subclades (see Fig. 4). The GenBank sequences utilised were from ticks collected in South Australia [29], while the sequences obtained during this study were from Victorian specimens. This pattern in the cox 1 sequences coupled with the geographic difference between the two groups suggests the group may be undergoing genetic differentiation.

The results of this study inform a number of historical questions and uncertainties concerning the subgenus Sternalixodes. Previously, Song et al. [14] used molecular techniques to assess the validity of the I. holocyclus species group. In the present study, based on the cox 1 and ITS-2 trees, it appears that $I$. myrmecobii and I. cornuatus are not subspecies of $I$. holocyclus, each being a valid species. This contradicts the suggestion made by Roberts [1] that these two species may be subspecies of the widespread I. holocyclus. The results of this study are congruent with the results of Song et al. [14] and Jackson et al. [13]. However neither of these studies included the Western Australian species, I. myrmecobii.

The findings of this study also provided insights into the validity of Sternalixodes as a subgenus. The apparent paraphyletic status of the subgenus based on the position of $I$. anatis in the cox 1 and morphological phylograms validates the suggestion by Heath [28] that the species should not be included in Sternalixodes. Heath [28] made the suggestion, citing the morphology of $I$. anatis as being incongruent with the morphological definition of Sternalixodes. Based on both morphological and $\operatorname{cox} 1$ data, it appears that I. anatis is not a sternalixodid tick and should not be included in the subgenus. This species does not meet the criteria of any of the subgenera of Ixodes defined by Clifford et al. [11]. However, Clifford et al. [11] noted that the classification of the subgenera of Ixodes was inaccurate in some situations, 
especially with regard to the subgenus Ixodes. An extensive examination of all existing subgenera using molecular and morphological data should be made in future to provide a more accurate hypothesis of the evolutionary relationships between the subgenera and the validity of the species within them. Based on the distinctive morphology of I. anatis and the fact that it does not meet the diagnostic requirements of any of the known subgenera of Ixodes, it may require the erection of a new subgenus. However more extensive molecular data should be accumulated and examined before this can occur.

Although seven of the nine species of Sternalixodes were examined in this study, molecular sequences and morphologically complete specimens were not located for I. confusus and I. cordifer. Although these species are most likely members of Sternalixodes, a complete molecular phylogenetic analysis including these species would be desirable to more accurately illuminate the evolutionary relationships within the subgenus.

As I. myrmecobii clusters within the I. holocyclus species group, a set of ticks known to cause paralysis, the question of its ability to also induce paralysis is raised. Tick induced paralysis has been extensively studied on the east coast of Australia; however, little information exists concerning ticks in Western Australia, let alone tick paralysis in Western Australia [9]. Studies of $I$. myrmecobii should be undertaken to determine if this species can induce paralysis. Roberts [30] and Kemp [31] noted that $I$. hirsti has been recorded to cause paralysis. Kemp [31] also proposed that all sternalixodid ticks may be capable of causing paralysis. As I. hirsti clustered with I. trichosuri and I. dendrolagi within the morphological and cox 1 phylogeny, it is possible that these species may also be capable of inducing paralysis, however, this should be investigated.

\section{Conclusion}

In conclusion, the cox1 and morphological data suggest that the subgenus Sternalixodes is paraphyletic, and I. anatis should not be included in this subgenus. Based on the phylogenetic analyses of $\operatorname{cox} 1$ and ITS- 2 sequences, it appears that I. myrmecobii and I. cornuatus are not subspecies of $I$. holocyclus, each being a valid species. Although this study has improved insights into the taxonomic status of the subgenus Sternalixodes, a complete morphological and molecular (using multiple markers) phylogenetic analysis including all nine species of the subgenus would be desirable to more accurately illuminate the evolutionary relationships within the subgenus.

\section{Abbreviations}

AIC: Akaike information criterion; BI: Bayesian inference; cox1: Cytochrome $c$ oxidase subunit 1 gene; ITS-2: Internal transcribed spacer 2; MCMC: Monte Carlo Markov Chain; ML: Maximum likelihood; NJ: Neighbour-joining

\section{Acknowledgements}

We are grateful to Tony Chiovitti and other staff from the Gene Technology Access Centre (GTAC), Melbourne for access to the scanning electron microscope. We are also thankful to Allen Heath (Ag Research, New Zealand) and Alberto Guglielmone (Instituto Nacional de Technologia Agropecuaria, Argentina), for both identifying and providing tick specimens for both morphological and molecular examination. In addition, we are indented to Mark Harvey Mestern Australian Museum), Ifor Owen (National Veterinary Laboratory, PNG) and Bruce Halliday (Australian National Insect Collection) for the provision of tick specimens.

\section{Funding}

This project was funded by the Early Career Researcher grant from The University of Melbourne, Australia (AJ).

\section{Availability of data and materials}

The data supporting the conclusions of this article are included within the article. The nucleotide sequences generated during this study are deposited in GenBank under the accession numbers KY213752-KY213793.

\section{Authors' contributions}

$\mathrm{MK}, \mathrm{IB}$ and $\mathrm{AJ}$ conceived the project and participated in the study design. MK carried out the laboratory work, data analyses, interpretation of data, and also drafted the manuscript, with guidance from co-authors. MK, AVK and AJ undertook phylogenetic analyses. IB and AJ participated in data interpretation and provided critical inputs on the draft manuscript. All authors read and approved the final manuscript.

\section{Competing interests}

The authors declare that they have no competing interests.

Consent for publication

Not applicable.

Ethics approval and consent to participate

Not applicable.

\section{Author details}

'Department of Veterinary Biosciences, Melbourne Veterinary School, Faculty of Veterinary and Agricultural Sciences, The University of Melbourne, Werribee, Victoria 3030, Australia. ${ }^{2}$ Centre for AgriBioscience, Department of Economic Development, Jobs, Transport and Resources, Bundoora, Victoria 3083, Australia. ${ }^{3}$ La Trobe University, Bundoora, Victoria 3083, Australia.

Received: 13 December 2016 Accepted: 17 February 2017

Published online: 02 March 2017

\section{References}

1. Roberts FHS. Australian ticks. Victoria: CSIRO Publishing; 1970.

2. Service M. Medical entomology for students. 3rd ed. Cambridge: Cambridge University Press; 2004.

3. Sonenshine DE, Roe RM. Biology of ticks, vol 2. 2nd ed. New York: Oxford University Press; 2014.

4. Barker SC, Walker AR, Campelo D. A list of the 70 species of Australian ticks; diagnostic guides to and species accounts of Ixodes holocyclus (paralysis tick), Ixodes cornuatus (southern paralysis tick) and Rhipicephalus australis (Australian cattle tick); and consideration of the place of Australia in the evolution of ticks with comments on four controversial ideas. Int J Parasitol. 2014:44:941-53.

5. Sexton DJ, Dwyer B, Kemp R, Graves S. Spotted fever group rickettsial infections in Australia. Rev Infect Dis. 1991;13:876-86.

6. St George TD, Doherty RL, Carley JG, Filippich C, Brescia A, Casals J, et al. The isolation of arboviruses including a new flavivirus and a new bunyavirus from Ixodes (Ceratixodes) uriae (Ixodoidea, Ixodidae) collected at Macquarie Island, Australia, 1975-1979. Am J Trop Med Hyg. 1985;34:406-12.

7. St George TD, Standfast HA, Doherty RL, Carley JG, Fillipich C, Brandsma J. The isolation of Saumarez Reef virus, a new flavivirus, from bird ticks Ornithodoros capensis and Ixodes eudyptidis in Australia. Aust J Exp Biol Med Sci. 1977;55:493-9.

8. Spratt DM, Haycock P. Aspects of the life history of Cercopithifilaria johnstoni (Nematoda:Filarioidea). Int J Parasitol. 1988;18:1087-92. 
9. Barker SC, Walker AR. Ticks of Australia. The species that infest domestic animals and humans. Zootaxa. 2014;3816:1-144.

10. Brown AF, Hamilton DL. Tick bite anaphylaxis in Australia. J Accid Emerg Med. 1998:15:111-3.

11. Clifford CM, Sonenshine DE, Keirans JE, Kohls GM. Systematics of the subfamily Ixodinae (Acarina: Ixodidae). 1. The subgenera of Ixodes. Ann Entomol Soc Am. 1973;66:489-500.

12. Jackson J, Beveridge I, Chilton NB, Andrews RH. Distributions of the paralysis ticks Ixodes cornuatus and Ixodes holocyclus in south-eastern Australia. Aust Vet J. 2007;85:420-4.

13. Jackson J, Chilton NB, Beveridge I, Morris M, Andrews RH. Genetic variation within the ticks Ixodes holocyclus and Ixodes cornuatus from south-eastern Australia. Int J Parasitol. 2000;30:1159-66.

14. Song S, Shao R, Atwell R, Barker S, Vankan D. Phylogenetic and phylogeographic relationships in Ixodes holocyclus and Ixodes cornuatus (Acari: Ixodidae) inferred from COX1 and ITS2 sequences. Int J Parasitol. 2011:41:871-80

15. Hardwick S. Electronic polytomous and dichotomous keys to the genera and species of hard ticks (Acari: Ixodidae) present in New Zealand. Syst Appl Acarol. 2010;15:163-83.

16. Werle E, Schneider C, Renner M, Völker M, Fiehn W. Convenient single-step, one tube purification of PCR products for direct sequencing. Nucleic Acids Res. 1994;22:4354.

17. Kearse M, Moir R, Wilson A, Stones-Havas S, Cheung M, Sturrock S, et al. Geneious Basic: an integrated and extendable desktop software platform for the organization and analysis of sequence data. Bioinformatics. 2012;28: 1647-9.

18. Goloboff PA, Farris JS, Nixon KC. TNT, a free program for phylogenetic analysis. Cladistics. 2008;24:774-86.

19. Lewis P. A likelihood approach to estimating phylogeny from discrete morphological character data. Syst Biol. 2001;50:913-25.

20. Huelsenbeck JP, Ronquist F. MRBAYES: Bayesian inference of phylogenetic trees. Bioinformatics. 2001;17:754-5.

21. Ronquist F, Huelsenbeck JP. MRBAYES 3: Bayesian phylogenetic inference under mixed models. Bioinformatics. 2003;19:1572-4.

22. Edgar RC. MUSCLE: multiple sequence alignment with high accuracy and high throughput. Nucleic Acids Res. 2004;32:1792-7.

23. Maddison WP, Maddison DR. Mesquite: a modular system for evolutionary analysis. Version 3.10, 2016. http://mesquiteproject.org

24. Tamura K, Stecher G, Peterson D, Filipski A, Kumar S. MEGA 6: molecular evolutionary genetics analysis version 6.0. Mol Biol Evol. 2013;30:2725-9.

25. Shao R, Aoki Y, Mitani H, Tabuchi N, Barker SC, Fukunaga M. The mitochondrial genomes of soft ticks have an arrangement of genes that has remained unchanged for over 400 million years. Insect Mol Biol. 2004; 13:219-24.

26. Hammer JF, Emery D, Bogema DR, Jenkins C. Detection of Theileria orientalis genotypes in Haemaphysalis longicornis ticks from southern Australia. Parasit Vectors. 2015:8:229.

27. Darriba D, Taboada GL, Doalla R, Posada D. jModelTest 2: more models, new heuristics and parallel computing. Nat Methods. 2012:9:772.

28. Heath ACG. Zoogeography of the New Zealand tick fauna. Tuatara. 1977;23: 26-38.

29. Chapman TW, Marando L, Oorebeek M, Kleindorfe S. Genetic structure in ixodid ticks from Kangaroo Island and the South Australian mainland. Aust J Entomol. 2009:48:40-6.

30. Roberts FHS. Tick paralysis in South Australia. Aust Vet J. 1961;37:440.

31. Kemp DH. Identity of Ixodes holocyclus and other paralysis ticks in Australia. Aust Adv Vet Sci. 1979;71:71.

\section{Submit your next manuscript to BioMed Central and we will help you at every step:}

- We accept pre-submission inquiries

- Our selector tool helps you to find the most relevant journal

- We provide round the clock customer support

- Convenient online submission

- Thorough peer review

- Inclusion in PubMed and all major indexing services

- Maximum visibility for your research

Submit your manuscript at www.biomedcentral.com/submit
Biomed Central 